\title{
Rotinas, estratégias e saberes de professores de Educação Física: um estudo de caso etnográfico
}

CDD. 20.ed. 371.1

796.017
Mônica Urroz SANCHOTENE* Vicente MOLINA NETO**

\section{Resumo}

0 presente artigo buscou identificar a constituição da prática pedagógica de professores de educação física e compreender qual a relação entre as experiências vividas pelos professores e a sua prática pedagógica. Desenvolvemos um estudo de caso etnográfico com sete professores de educação física de uma escola pública da Rede Municipal de Ensino de Porto Alegre (RMEPOA). Foram realizadas oito entrevistas semiestruturadas e 200 horas de observação participante. A pesquisa está fundamentada nas teorias da ação e na nova epistemologia da prática. Identificamos que os professores desenvolvem rotinas e estratégias criativas, baseadas fundamentalmente em suas experiências vividas, para alcançar os objetivos de suas aulas e que sua prática pedagógica está relacionada aos saberes que os mesmos produziram ao longo de seu ciclo de vida. 0 estudo foi apresentado aos colaboradores como forma de validação da pesquisa e de estabelecer um diálogo que propiciasse aos professores refletir sobre as suas práticas.

PalaVRas-chave: Educação física; Prática pedagógica; Experiências vividas; Formação de professores.

\section{Introdução}

Em recentes publicações na área da educação física encontramos uma vasta discussão a respeito dos dilemas na formação inicial, do descompasso entre o currículo dos cursos superiores e a prática pedagógica cotidiana na escola, da abrangência dos esportes nas aulas de educação física, dentre outras ${ }^{1-4}$. Baseando-nos nessas publicações, dirigimos nossa atenção e interesse à compreensão sobre qual a relação que se estabelece entre as experiências vividas pelos professores de educação física e a sua prática pedagógica desenvolvida nas escolas da Rede Municipal de Ensino de Porto Alegre, RS, (RMEPOA).

Esta pesquisa fundamenta-se, teoricamente, nos autores Pierre Bourdieu e Bernard Lahire na área da sociologia, e nos debates em torno da nova epistemologia da prática desenvolvidos por Perrenoud $^{5-6}$, Silva ${ }^{7}$, Tardif e GauthieR ${ }^{8}$, TardiF e LESSARD ${ }^{9}$, os quais têm realizado ensaios teóricos e pesquisas empíricas a respeito dos saberes, das rotinas e das estratégias que os professores utilizam para suprir as demandas da prática pedagógica.

\section{A prática pedagógica}

Ao procurar compreender a constituição da prática pedagógica de professores de educação física subsidiamonos no conceito de prática de Bourdieu ${ }^{10}$, para quem

A prática é, ao mesmo tempo, necessária e relativamente autônoma em relação à situação considerada em sua imediatidade pontual, porque ela éo produto da relação dialética entre uma situaçãao e um habitus entendido como um sistema de disposiçōes duráveis e transponíveis que, integrando todas as experiências passadas, funciona em cada momento como uma matriz de percepçōes, apreciaçōes e ações - e torna possível a realização de tarefas infinitamente diferenciadas, graças às transferências analógicas de esquemas, que permitem resolver os problemas da mesma forma, e às correçōes incessantes dos resultados obtidos, dialeticamente produzidas por esses resultados (p.65).

O autor considera que o "habitus" é o produto da história individual e coletiva e pode ser entendido como princípio gerador e estruturador de práticas e das representaçóes ${ }^{10}$ (p.60-1) [grifo nosso].
*Rede Municipal de Ensino - Porto Alegre. **Escola de Educação Física, Universidade Federal do Rio Grande do Sul. 
Na concepção de PerRenOUd ${ }^{6}$, a ação pedagógica dos professores é constantemente orientada por um "habitus" moldado pela interiorização de um aprendizado baseado em tentativas e erros e pela seleção das respostas adequadas ao meio físico e social, agindo como uma gramática geradora das práticas. Assim, os professores produzem rotinas que são colocadas em ação sem avaliar seu caráter arbitrário. $\mathrm{O}$ autor diz, ainda, que há uma tendência racionalista e que, por várias razões, a prática é apresentada como sendo mais consciente e racional do que o é na realidade. PERRENOUD ${ }^{6}$ enfatiza que muitas das ações e rotinas desenvolvidas pelos professores não são conscientes. Nesse sentido, utiliza a noção de "habitus" com o intuito de romper com a imagem racionalista e simplificada da ação, procurando entendê-la em seus aspectos não conscientes, em suas motivações, improvisações e rotinas.

Perrenoud trata da gestão da urgência e concorda com Bourdieu ao ressaltar que "[...] não reagimos ao acaso, mas em função de nosso habitus, na ilusão da espontaneidade e da liberdade"6 (p.168). Portanto, o "habitus" também é investido na preparação das aulas, em sua organização e na escolha das atividades, traduzindo a nossa capacidade de operar "sem saber", em uma rotina econômica ou para fazer face às emergências do cotidiano. Em toda ação complexa, mesmo em situação de urgência ou no quadro de uma rotina, manipulamos informações, representações, conhecimentos pessoais e saberes sociais; "[...] mas é o habitus que governa esses tratamentos" ${ }^{6}$ (p.170).

No Brasil, SiLva ${ }^{7}$ centra seu interesse em "[...] investigar como se aprende para ensinar na sala de aula" (p.154). Para tanto, a autora utilizou a teoria da ação prática, ressaltando que, para Bourdieu, "[...] práticas deixam de ser meros saberes práticos e configuram um comportamento que denominou habitus" (p.156). Ao relacionar "habitus" e experiência, a autora considera que são "[...] duas noçôes fundamentais aos estudos sobre o lugar da teoria e da prática na formação e atuação docentes, tendo em conta a estruturação do objeto de estudo das investigaçóes sobre o ato de ensinar na sala de aula"7 (p.158).

Partindo dessa base teórica e de pesquisas empíricas, SILVA ${ }^{7}$ denomina "habitus" professoral

[...] o conjunto de açóes que visivelmente eram exercidas pelo professor e pelas professoras (respectivamente, um professor e três professoras) observados, que recebiam respostas imediatas, objetivas e espontâneas de seus alunos, que estabeleciam relação direta com os gestos de ensino decididamente intencionais praticados por esses profissionais (p.158).
A autora lembra, ainda, que "[...] um habitus pode ser reestruturado com outras práticas, configurando outro habitus" (p.159). E conclui, dizendo que,

[...] durante a formação os discentes estruturam o

habitus estudantil, e não o habitus professoral, pois o último será desenvolvido somente no e com o exercício da docência. E é exatamente por isso que se afirma que $o$ ato de ensinar na sala de aula denominase habitus, e não prática docente, sobretudo quando o que está em jogo é a constituição do objeto das investigações sobre o ensino na sala de aula (p.160).

Mesmo concordando com as teorizaçōes dos autores acima citados, sobretudo no que se refere à utilização da noção de "habitus" para a compreensão das práticas pedagógicas, pensamos que a prática pedagógica não se trata, exclusivamente, de um "habitus". Entendemos que o "habitus" constitui a prática, inclusive inconscientemente. Isto porque os professores, durante a sua própria escolarização, e por meio de distintas vivências, incorporam disposiçōes para a ação; ou seja, incorporam expectativas em relação aos alunos e ao funcionamento da escola que vêm a ser fundamentais nas tomadas de decisōes ao orientar suas práticas. Desse modo, as experiências vividas pelos professores são incorporadas e constituem suas disposições para a ação, seus esquemas de julgamento e de avaliação, e tendem a influenciar a organização das aulas e a organização escolar.

Entendemos que as rotinas dos professores são orientadas por um "habitus" precocemente constituído. Assim, podemos dizer que o "habitus", ou de modo mais específico, as predisposiçóes para a ação, interferem no planejamento e execução das aulas e nos padrōes de avaliação e de comportamento, estando presentes no planejamento das aulas e no relacionamento do professor com os alunos. E, para Bernard LAHIRE ${ }^{11}$,

[...] a criança, o adolescente e, depois, o adulto não incorporam propriamente falando 'estruturas sociais', mas hábitos corporais, cognitivos, avaliadores, apreciativos, etc., isto é, esquemas de ação, maneiras de fazer, de pensar, de sentir e de dizer adaptadas (eàs vezes limitadas) a contextos sociais específicos (p.173).

De outro ponto de vista, TARDIF e LESSARD 9 ressaltam que, no plano das atividades cotidianas, o trabalho dos professores apoia-se em rotinas e tradiçôes: "os professores entram nas classes, tomam a palavra, apresentam a lição do dia, etc." (p.42). Porém, os autores reconhecem que há uma parte do trabalho flexível - elementos informais, incertezas e variáveis - considerando que se trata "de um trabalho cujo produto ou objeto sempre escapa, em diversos aspectos à ação do trabalhador, enquanto o mesmo não acontece em muitíssimas outras atividades [...]”9 (p.43). 
No entanto, para GAUTHIER et al..$^{12}$, "os saberes nos quais os professores se apoiam dependem diretamente das condiçōes sociais e históricas nas quais eles exercem a sua profissão (p.343)". O autor complementa a ideia ressaltando que os saberes dos professores somente podem ser compreendidos se relacionados às condiçôes que estruturam seu trabalho.

\section{Método}

Ao considerarmos o objetivo da investigação: Compreender qual a relação que se estabelece entre as experiências vividas pelos professores de educação física e sua prática pedagógica desenvolvida nas escolas da Rede Municipal de Ensino de Porto Alegre (RMEPOA), optamos por uma pesquisa qualitativa, de caráter etnográfico. NEGRINE ${ }^{13}$ observa que o paradigma qualitativo, mais especificamente a etnografia, "[...] passa a ser utilizada no campo da educação, fundamentalmente em estudos que se propōem a investigar relações e comportamentos complexos e subjetivos como os que ocorrem no âmbito escolar” (p.61).

Interessamo-nos por realizar a pesquisa na RMEPOA devido a importância e a visibilidade que esta Rede vem recebendo em todo o Brasil devido a mudanças educativas importantes que estão ocorrendo, tais como, a organização do currículo por ciclos de formação e a integralidade no ensino fundamental ${ }^{14}$.

Entendemos que o estudo da prática pedagógica dos professores que integram esta rede é uma forma de ampliar o conhecimento do interior da escola. Através de um estudo de caso etnográfico identificamos mudanças nas aulas dos professores de educação física, buscando a compreensão da educação física escolar a partir de práticas concretas e evitando prescrições aos professores. Assim, visamos aproximar os conhecimentos acadêmicos com os saberes das experiências docentes dos professores, examinando seus pontos de encontro e de desencontro.

Iniciamos a pesquisa de campo com o estudo preliminar em uma escola da RMEPOA e, ao longo deste, percebemos que a escola configurava-se em um ambiente adequado ao estudo de caso, por ter oito professores de educação física em efetivo exercício e com diferentes tempos de trabalho no magistério e distintas experiências docentes (ver ANEXO 1). Apenas uma das professoras optou por não participar porque estava trabalhando como coordenadora de turno e coordenadora das escolinhas esportivas.Através do quadro de caracterização dos professores participantes
Sendo assim, as aulas que os professores estão propondo hoje aos seus alunos não são somente uma ação criativa singular e individual do sujeito, mas o conjunto de predisposições para a ação ou "habitus" consolidados no seio de determinada cultura docente histórica e socialmente situada.

da pesquisa (ANEXO 1) podemos identificar que o grupo de professores da Escola é bastante diversificado no que se refere ao tempo de serviço no magistério e na escola em questão, alguns estão voltados para o trabalho com escolas, enquanto que outros diversificam seu trabalho, embora atuem na área da Educação Física.

O estudo de caso etnográfico estendeu-se por um ano, além do estudo preliminar de três meses. Participaram sete professores de educação física, os quais serão tratados por nomes fictícios, a fim de garantir o sigilo da fonte, e optamos por nomear a escola de Escola Restinga. O projeto de pesquisa foi submetido ao conselho de ética da Universidade e os participantes assinaram o Termo de Consentimento Livre e Esclarecido. Todos autorizaram a divulgação dos depoimentos e das demais informações para fins de publicação científica ou apresentação de trabalhos em eventos científicos. A íntegra dessas informações está registrada nos termos do processo no 2006570, aprovado em 22/06/2006.

A realização do estudo preliminar permitiu o refinamento dos instrumentos para obtenção de informações a serem utilizadas, em especial a entrevista semi-estruturada, a organização da escrita do diário de campo e o olhar durante a observação participante. O estudo preliminar, realizado por ocasião da elaboração do projeto de pesquisa, foi utilizado no trabalho final por opção dos pesquisadores, totalizando 40 horas de observação participante na escola, centradas na prática pedagógica de dois professores de educação física. Ainda realizamos duas entrevistas semi-estruturadas e analisamos os planejamentos de educação física das turmas observadas.

Durante a pesquisa, utilizamos como fontes de obtenção de informações a observação participante por um tempo de 200 horas, entrevistas semi-estruturadas (sete entrevistas com professores de educação física e uma com a diretora da escola), análise de documentos (planejamento dos professores, avaliação trimestral, planta da escola, dentre outros) e entrevista escrita 
ou narrativa (de acordo com a disponibilidade dos professores). A professora Eliane optou por reescrever parte de sua entrevista, pois entendeu que seria a forma mais adequada para explicitar seu pensamento. As entrevistas foram transcritas e os professores tiveram a oportunidade de lê-las e validá-las para sua posterior inserção na pesquisa. No final da entrevista transcrita havia um espaço destinado a uma narrativa escrita para os professores que desejassem fazê-la. Porém, poucos professores acrescentaram alguma ideia a essa solicitação.

Todas as observações foram anotadas em diário de campo e, posteriormente, digitadas. A pesquisa foi apresentada aos professores colaboradores do estudo como forma de validá-la ${ }^{15}$ e para estabelecer um diálogo com esses professores.

\section{Resultados e discussão}

Os resultados da pesquisa foram organizados em três tópicos, do seguinte modo: a) as rotinas da prática pedagógica, apresentando quais fatores influenciam na organização da prática cotidiana dos professores; $b$ ) as estratégias da prática, expresso pela forma com que os professores superam as dificuldades encontradas no dia-a-dia escolar, e c) a prática pedagógica, com seus conhecimentos e seus saberes, apresentando quais conhecimentos e saberes foram mobilizados pelos professores durante as aulas de educação física.

\section{As rotinas da prática pedagógica}

Identificamos que os professores que colaboraram com o estudo organizavam suas aulas baseados em rotinas e em reflexões sobre a prática. $\mathrm{Na}$ maior parte das vezes, essas reflexóes tinham a própria prática como parâmetro. No dizer de PerRENOUD ${ }^{6}$, a prática de um professor se desenvolve a partir de um número impressionante de rotinas que vão fazendo parte de seu "habitus" e se constituem em saberes procedimentais, que vão crescendo à medida que se avança no ciclo de vida profissional.

Nessa perspectiva, e mediante as observaçōes participantes de aulas e das entrevistas, foi possível identificar que os professores justificam de diferentes formas a utilização de rotinas nas aulas. $\mathrm{Na}$ entrevista, a professora Eliane relatou que segue algumas rotinas que acredita serem necessárias para a manutenção da organização escolar:

Eu busco eles [os alunos] na sala, normalmente eu

faço a chamada, como eu de repente passei o ano
Optamos por um processo analítico com categorias abertas, ou seja, categorias construídas a partir dos dados de campo e utilizando a identificação de unidades de significado relevantes. As categorias de análise foram construídas ao longo do estudo, pois, conforme ANDRÉ ${ }^{16}$, procuramos organizá-las com base em um diálogo constante entre a teoria e os dados obtidos, estabelecendo o confronto do referencial teórico com as observações e com as entrevistas. Em diversos momentos tivemos dificuldade em estabelecer as fronteiras entre uma categoria e outra, talvez pelo fato de a prática ser extremamente ampla e complexa, dificultando a produção de rupturas, mesmo que estas tenham sido feitas no intuito de aprofundar a análise.

inteiro com problema de voz, eu normalmente faço assim. Eu faço a chamada em sala. Normalmente eu explico já na sala, comecei a explicar na sala a atividade que a gente vai fazer na quadra. Para facilitar. E quando eles chegam na quadra eles já sabem o que vão fazer. Esperar na quadra nem pensar. Porque eles vão no banheiro e não voltam nunca mais, imagina se a professora abrir a porta e disser: - agora vocês vão tudo para a quadra que a professora está lá. Não dá, não tem como. Como eu trabalho com os pequenos, nenhuma turma, eu acho, talvez os grandes. Só os grandes. Mas eu acho que os de $\mathrm{A}$ e $\mathrm{B}$, todos os alunos, os professores vão na sala buscar (Eliane, entrevista em 30/08/2006).

Não, não foi determinado. [...] porque o que acontecia era o seguinte, os alunos não vinham, não vinham, não vinham. Não liberavam. E aí começou correria... e então eu acho que em função de controle, eu acho que em função de não ter aluno circulando, fora da sala de aula, foi que se... mas não foi determinado: não. Eu não me lembro de alguém ter dito não, vocês tem que ir na sala de aula pegar o aluno. No jardim claro, tem que pegar. Mas os outros, não, ninguém determinou que tinha que ir na sala buscar. Foi uma coisa que acabou acontecendo... naturalmente (Eliane, entrevista em 30/08/2006). A professora Glória, que estava fazendo o Curso de Especialização em Esporte Escolar, desenvolve rotinas com o objetivo de estimular a autocrítica dos alunos: A gente sempre tem o primeiro momento na sala de aula, porque eu busco os alunos na sala. Então, ali na 
sala, são colocados os objetivos, o que eu pretendo com eles, que atividades nós vamos fazer. Às vezes eles propõem atividades. Por exemplo, sempre, naquela primeira parte, de descontração, de aquecimento, eu sempre busco uma brincadeira deles, algo que eles me trazem. [...] Sempre uma brincadeira já conhecida, depois eu ponho uma nova, uma minha. Para que eles [...] vão aumentando os seus conhecimentos. Depois eu entro na atividade que eu vou direcionar para aquele objetivo que eu quero. Se eu estou trabalhando futsal e quero que eles desenvolvam melhor a questão de passes eu vou fazer várias atividades, em forma de jogos, de brincadeiras, para que eles desenvolvam esse passe, para concluir com um jogo, um grande jogo, onde todo mundo joga ou nos jogos, nas equipes menores. Quando estiver mais avançado, equipes menores. Finalizando sempre com uma conversa: como foi, o que aconteceu, alguém ficou de fora, e porque ficou. Para se colocar, para fazer com que eles façam esse conhecimento. Se alguém ficou de fora, normalmente as meninas, se é o jogo... eu saí porque o fulano não me passa a bola, porque não sei o quê. Então, essas coisas todas que passam... que são próprias do grupo (Glória, entrevista em 03/10/2006).

Sempre procurando que eles tenham uma autocrítica de como foi o seu desenvolvimento. Como eu busco um conhecimento deles e uma interação deles em função das discriminações, eles têm que fazer uma crítica. Porque se aquele, por exemplo, que discriminou o outro porque ele não sabia jogar ele tem que entender que ele está num processo diferente, que o direito é de todos, que o espaço é de todos... não é exclusivo dele porque ele já domina alguma habilidade. Então sempre baseado nisso, buscando uma crítica... minha mesmo. [...] Também tem que ter esse retorno para eu poder ver outras formas de interagir com eles para que o trabalho realmente ande (Glória, entrevista em 03/10/2006).

Já, para o professor Denis, a escola tem "rituais": É que eu acredito que a escola tem rituais. E acho que esses rituais são importantes. Tu tens que dar o conhecimento que está começando. Então o que eu uso, qual é o meu ritual? [...] Eu vou buscá-los na sala de aula, nunca combino que eles venham aqui embaixo. Vou na sala de aula, faço combinações iniciais, digo o que vai acontecer e nesse momento a gente negocia. É um espaço menor, não precisa gritar tanto. Não gritar de brigar, mas falar tão alto para que possa ser ouvido. Então eu uso isso, faço chamada na sala de aula e depois nós descemos. Mas hoje eu acho importante a gente reunir os alunos na sala de aula, conversar com eles, organizar o negócio, descer... se dá alguma confusão aqui embaixo eu volto para a sala de aula, que é um ambiente menor e a gente vai poder discutir o que aconteceu, não tenho problema nenhum de interromper uma aula e subir com eles. Faço isso eventualmente, mesmo que eles protestem. Porque eu acho que algumas coisas a gente tem que ter (Denis, entrevista em 31/10/2006).

Esse professor também relatou que as muitas tarefas da vida cotidiana ( 40 horas de trabalho semanal, mestrado, comissão da Associação de Trabalhadores em Educação do Município de Porto Alegre, entre outros) o absorviam e ele não conseguia dedicar mais tempo à preparação das aulas: "Quando chego na escola acabo fazendo o que sempre fiz e que dá certo" [...] (Denis, trecho do diário de campo, dia 06/04/2006).

Deduzimos que isto não se deve, exclusivamente, a uma vontade do professor de repetir as mesmas aulas, mas está vinculado a fatores como a intensificação do trabalho docente. Para Hargreaves ${ }^{17}$, o fenômeno da intensificação consiste de maiores expectativas em relação ao trabalho dos professores, exigências mais amplas, com mais responsabilidades ligadas ao trabalho social, que promovem uma sobrecarga crônica de tarefas. Portanto, a utilização de rotinas pode estar relacionada à intensificação e à constituição de um "habitus" baseado nas práticas que deram certo:

Já tentei outras coisas e não tive competência para

dar conta. Tentei um ano trabalhar com expressão corporal e com outras vivências e tal e não rolou. Foi um troço que, absolutamente, eu não consegui fazer e não consegui nem negociar com eles, porque não tinha disposição. Eles não tinham disposição para isso e a minha disposição [...] acabou terminando. E aí o esporte foi uma coisa que me facilitou a vida

(Denis, entrevista em 31/10/2006).

Segundo Perrenoud 6 , o "habitus" profissional desenvolve-se mediante rotinas e ações que deram certo e que tendem a influenciar a organização das aulas. Mesmo que o professor procure refletir sobre a sua prática, através de cursos de pós-graduação, por exemplo, em alguns momentos pode se sentir 'engolido' pela intensificação. A discussão a respeito da intensificação no trabalho docente dos professores da RMEPOA está presente em WiTTIZORECKI e Molina NeTO ${ }^{18}$.

Para a professora Ana, as combinações com os alunos são importantes, a fim de organizar melhor suas aulas:

Eu sempre combinei com eles assim: vamos fazer a chamada e a gente vai fazer uma atividade de concentração. No início eu fazia mais de concentração e explicava: para vocês conseguirem focar, se acalmar, para eu poder explicar as coisas. Então eu trazia, 
normalmente eu tinha um cartaz com uma mandala, um desenho e pedia para que eles ficassem olhando, focando, respirando. E eu estabeleci... não cheguei a perguntar, ah, o que vocês acham? Provavelmente, eles não iriam dizer que sim porque eles não conhecem isso, não faz parte da cultura deles. E depois eu explicava as atividades, construía a fila - que isso foi uma amiga minha que ensinou - eu sempre fiz sorteio de quem vai começar a fila. Eles batem na mesa de alguém e vem para a fila, batem na mesa de alguém e vem para a fila... (Ana, entrevista em 21/08/2006).

As rotinas parecem fazer parte do dia-a-dia dos professores, tanto no sentido de dar conta de suas tarefas e de organizar o ambiente escolar, quanto no de abrir espaços de crítica para os alunos. Desse modo, a produção de rotinas pode vir a ser um instrumento de reprodução das práticas e de manutenção de uma ordem estabelecida ou uma possibilidade de questionamento dessa ordem, dependendo da concepção do professor na organização das aulas.

A possibilidade de reflexão aprofundada sobre a prática, fundamentando-a teoricamente, tende a produzir rotinas que favoreçam a crítica ao ambiente escolar e às aulas, enquanto que as rotinas organizadas no intuito de se adequarem ao espaço escolar podem servir de instrumentos na manutenção da estrutura escolar. Sendo assim, podemos dizer que o contexto escolar e suas regras (sejam elas escritas ou não), juntamente com a intensificação do trabalho docente, favorecem a constituição e o desenvolvimento de rotinas.

Porém, ao procurarem mudar suas aulas, no que se refere aos conteúdos ou à alteração das rotinas que facilitam sua organização, observamos que os professores se deparavam com fatores que dificultavam a sua superação. Ao acompanhar a professora Flávia nas aulas, nas quais pretendia trabalhar determinada coreografia com os alunos, pudemos perceber os limites de se trabalhar com este conteúdo, ou seja, de produzir uma mudança no que está estabelecido - aulas com conteúdos esportivos. Observamos o desenvolvimento da coreografia proposta por essa professora durante dois meses de trabalho, com um período de aula por semana, totalizando nove aulas. Destas, apenas cinco vezes a aula foi realizada como a professora havia planejado (conversávamos antes das aulas e ela me contava o que estava planejado para aquele dia). Ainda assim, por duas vezes esta atividade foi realizada na sala de aula, ambiente pequeno em relação à quantidade de alunos. No dia em que a turma foi para o ginásio havia problema na corrente de luz e, consequentemente, a atividade foi realizada de forma adversa (o aparelho de som não funcionou por falta de energia e os alunos tiveram que cantar a música e dançar ao mesmo tempo). Algumas mudanças de horários, os conselhos de classe, as solicitações do Serviço de Supervisão Escolar (SSE) a respeito das avaliações dos alunos, também influenciaram negativamente o andamento destas aulas.

Deste modo, identificamos que a produção de rotinas pode estar voltada para a manutenção da ordem vigente na escola ou para o seu questionamento. No entanto, na tentativa de produzir mudanças nas aulas de educação física os professores tiveram dificuldades de diferentes ordens.

\section{As estratégias da prática}

Em relação às estratégias da prática, a professora Glória, ao não se conformar com as limitações do ambiente escolar, produz estratégias de sobrevivência ${ }^{19}$. Após a entrevista, ela nos mostrou o material alternativo para o trabalho com os alunos. Este material foi confeccionado por ela, com o auxílio de seus familiares e, em alguns casos, com o auxílio dos alunos. Observamos que a professora Glória chegava às aulas com sacolas de pano, bolas de meia, braceletes, dentre outros materiais (Diário de campo, 31/10/2006), indo ao encontro do que ressaltam WITTIZORECK e Molina Neto $^{18}$ de que grande parte do coletivo de professores da escola pública revela "[...] um sentimento de luta, resistência, criatividade e esperança que os move frente a esses obstáculos” (p.48).

A professora Glória participou do Curso de Especialização em Esporte Escolar, no formato de Ensino a Distância, através do Programa Segundo Tempo $^{\mathrm{a}}$, o que lhe possibilitou o contato com a bibliografia recente da área (relato da professora posterior à entrevista e descrita no diário de campo) e a reflexão mais aprofundada sobre sua prática. Sua dedicação é reconhecida por colegas: "a Glória tem uma bagagem bem legal. Eu tenho observado que ela confecciona muito material, ela tem uma dedicação que eu, eu assumo, que eu não tenho. De buscar alternativas, de confeccionar outros materiais [...] (Eliane, entrevista em 30/08/2006).

Os professores que têm a possibilidade de se manterem em constante atualização, a exemplo de Glória (Curso de Especialização em Esporte Escolar) e de Denis (Mestrado em Educação) parecem produzir reflexões mais aprofundadas a respeito de suas aulas e, algumas vezes, conseguem mudar alguns aspectos de sua prática. O professor Denis tece algumas críticas ao seu trabalho, mas também consegue observar alguns avanços: 
E os conceitos que eu venho estudando, o conceito de poder, as relaçôes de gênero, também são coisas que eu me preocupo, que eu acho interessante. Acho que é uma conquista que a gente teve nessas minhas turmas que eles conseguem... essa questão de gênero, da divisão, dessa dicotomia grande entre meninos e meninas é bem legal que a gente consegue superar, de alguma forma. Eu acho que rola. E faço essas coisas e acho que essas coisas rolam dessa forma pelos estudos que venho fazendo. Acho que colabora muito sim. Não para que a gente consiga o ideal. Ou algo que seja bem interessante, que funcione como um relógio, mas colaborar para que a gente consiga nesse nosso caos ir organizando as coisas, temporariamente (Denis, entrevista em 31/10/2006).

Em uma reunião pedagógica por disciplina, na qual estávamos presentes, esse professor falou sobre a amplitude do que se ensina nas aulas em relação ao planejado:

[...] o que está no planejamento é uma coisa; a aula, o que acontece nas aulas, é outra. Tratamos de diversos assuntos que não estão escritos em lugar nenhum, como a roupa adequada, o encurtamento muscular causado pelos saltos altos, etc. (Denis, trecho do diário de campo, dia 06/04/2006).

Entre as estratégias utilizadas pelos professores, em sua prática bastante peculiar, a professora Ana desenvolve a meditação e a concentração com seus alunos, e busca conhecimentos em outras áreas para subsidiá-la: "Onde é que eu vou buscar recursos pra melhorar nesse sentido? Há recursos fora, em áreas que eu acredito, como o Yoga, teatro e tal" (Ana, entrevista em 21/08/2006). No entender de Ana, esses conhecimentos estão baseados em sua formação: "Olha, estão baseados na minha formação, mas não tanto acadêmica, mais nesses caminhos assim que eu vou buscar de educação e valores humanos do Sai Baba ou no Yoga ou essa questão mais oriental mesmo" (Ana, entrevista em 21/08/2006).

Entendemos que a professora Ana está construindo uma estratégia diferenciada em relação aos outros professores. Ela procura subsídios para sua prática em outras áreas - Yoga e teatro -, enriquecendo suas aulas e apresentando aos alunos novas possibilidades - meditação e concentração.

Um dos aspectos que nos chamou a atenção na observação do trabalho da professora Ana foi o caderno no qual anota o planejamento de suas aulas. Ao ter acesso a este caderno constatamos a existência de um plano escrito das aulas da semana e, embora não seja detalhado, nele constam as atividades a serem desenvolvidas e, algumas vezes, o objetivo trabalhado naquela semana. Para LAHIRE ${ }^{11}$, a utilização da escrita tem, basicamente, duas funções: a primeira seria a de objetivar o que ainda não foi totalmente incorporado e, quando os programas tiverem sido incorporados, "[...] a memória interna substituirá progressivamente a memória objetivada externa” (p.120); a segunda função seria uma possibilidade de ruptura com o senso prático. $\mathrm{O}$ autor observa que

estas práticas representam verdadeiras rupturas com relação ao senso prático, com a lógica prática, e podem ser compreendidas a partir da relação negativa que mantêm com a memória prática, incorporada, do habitus. Tornam possível o domínio simbólico de certas atividades, bem como sua racionalização ${ }^{11}$ (p.117).

Nessa perspectiva, a professora Glória utiliza a escrita e não vai para a aula sem o seu caderno, que, além de ter a função de planejamento, serve de apoio para as aulas, partindo do conteúdo que está sendo desenvolvido, tratando das atitudes dos alunos, dentre outros aspectos. Consideramos que a utilização da escrita por professoras que se encontram em diferentes momentos da carreira docente pode estar servindo a funções distintas. LAHIRE ${ }^{11}$ destaca que, com o passar dos anos, há um desinvestimento na utilização da escrita, pois, para os professores na fase inicial da carreira, sua utilização se deve à dificuldade de interiorizar alguns aspectos da profissão, e, à medida que as disposições vão sendo incorporadas, esse investimento é minimizado. Para os professores com mais tempo de trabalho na docência, a escrita pode servir para promover rupturas com o senso prático.

A partir do exposto, inferimos que, em alguns momentos, os professores conseguem superar as aulas baseadas nas rotinas e no senso prático ("habitus") e produzem algumas mudanças em suas práticas pedagógicas. Entendemos que a reflexão aprofundada e a utilização da escrita podem estar auxiliando a promover mudanças nas rotinas dos professores, seja no sentido de modificação das práticas ou na utilização de estratégias de sobrevivência.

\section{A prática pedagógica: seus conhecimentos e seus saberes}

Encaminhamos a discussão a respeito dos conhecimentos e dos saberes da prática ressaltando que [...] o conhecimento que se mobiliza para enfrentar as situaçôes divergentes da prática é do tipo idiossincrático, construído lentamente pelo profissional no seu trabalho diário e na sua reflexão na e sobre a ação. O conhecimento das ciências básicas tem um indubitável valor instrumental, desde que se integre no pensamento prático do $\operatorname{professor}^{20}$ (p.111). 
Desse modo, buscamos compreender a prática pedagógica não como algo necessariamente pensado, planejado, refletido, mas, ao mesmo tempo, procurando evitar a noção de uma ação automática, ou seja, entendendo que a prática pedagógica constituise, também, de um conhecimento produzido pela reflexão a partir da prática.

A noção de saber a ser utilizada neste estudo aproxima-se da concepção de TARDIF e GAUTHIER ${ }^{8}$, quando observam que

[...] o saber dos professores é uma razão prática, social e voltada para o outro, porque, o professor também se baseia, para atingir os objetivos pedagógicos, em julgamentos que provêm de tradições escolares, pedagógicas e profissionais, os quais ele próprio assimilou e interiorizou. Ele se baseia, finalmente, em sua "experiência vivida” como fonte viva de sentido, a partir da qual o passado permite-lhe esclarecer o presente e antecipar o futuro (p.202).

Sendo assim, a noção de saber dos professores estará ancorada nos conhecimentos e nas práticas, sejam estas anteriores à sua formação ou provenientes de sua prática pedagógica. A esse respeito, as falas dos professores Beto, Ana e Carlos são bastante ilustrativas: Então eu trabalho dentro das condições que nós temos, dentro também, um pouco, da minha experiência. A minha experiência como professor é mais voltada para o esporte. [...] Eu realizo as aulas procurando dar as informaçóes relacionadas ao esporte. Relacionar o esporte com a parte de fundamentos... tanto na prática como também na teoria, regras, e as relações de convivência, entre os alunos também [...] (Beto, entrevista em 30/11/2005).

Eu me baseio muito nos anos anteriores. Busco, claro, o que eu vou trabalhar, coordenação motora geral, mas eu não foco numa coisa só. Eu gosto muito de trabalhar com circuito, eu acho que é divertido... eu sinto que eles gostam. E o circuito eu acho que é uma coisa que tu consegues colocar vários elementos, principalmente com relação à coordenação motora geral. E gosto muito de trocar também com os colegas, com as pessoas (Ana, entrevista em 21/08/2006).

O handebol eu não tenho muita simpatia, não sei, acho que é uma resistência de quem praticou basquete, então fica meio preconceituoso com handebol, hoje já estou mais aberto [...] (Carlos, entrevista em 01/12/2005).

Para as professoras Eliane e Flávia, as suas vivências e a própria prática parecem ser parâmetros fundamentais para suas reflexões e para o seu planejamento:
Olha, eu, após 19 anos de profissão, eu já trabalho bastante também com as minhas vivências, mas procuro fazer cursos, aperfeiçoar, ver o que está acontecendo de novo. Mas utilizo ainda, bastante, do que eu aprendi na faculdade (Flávia, entrevista em 19/09/2006).

Utilizo as atividades dos anos anteriores que funcionaram bem e que tiveram boa aceitação entre os alunos. Eu penso em primeiro lugar no perfil das turmas que eu vou trabalhar, verifico se a atividade não vai agitar demais os alunos, se não é muito agressiva e, principalmente, se os alunos têm condiçôes de entender a brincadeira. Às vezes vejo atividades de outras turmas e converso com o colega, se não tiver problema eu utilizo nas minhas aulas (Eliane, entrevista dia 30/08/2006).

Já, no caso da professora Ana, o que ela traz de sua escolarização para a reflexão é que as suas vivências escolares são uma realidade a ser superada. A professora utiliza conhecimentos de outras áreas e organiza suas aulas com conhecimentos diferentes dos vivenciados nas escolas e nas escolinhas esportivas das quais participou.

Eu busco muito isso na minha prática, busco muito na área da cooperação, que eu não tive formação nisso. E, com relação às minhas experiências pessoais esportivas, eu sempre competi, sempre fui atleta, joguei na SOGIPA (Sociedade Ginástica Porto Alegre) um tempão e gosto de jogar, mas o que eu tenho trabalhado, e foi o que me trouxe de experiência, é que o jogo, por mais que tu queiras que todo mundo participe, todo mundo... não adianta, sempre tem velado uma coisa de que tu queres ganhar e que tu vais rejeitar aquele que não joga. Concordo com o trabalho que a Glória fez. Eles rejeitam pela habilidade. Acho que essa minha experiência como atleta me traz isso, de ter muito esse cuidado. Porque a competição, eu, pessoalmente, acho que não deve ser a ênfase na escola (Ana, entrevista em 21/08/2006).

Porque eu sempre sofri muito com essa coisa, por exemplo, de fila por tamanho. Sempre tive o desejo de ser a primeira e nunca fui, sempre fui a grande... Então eu acho que tem o momento sim para eles escolherem quem vai. E, nesse sentido, eles já sabem, quem fica atrás de quem ... e...isso no primeiro ano. Eu sempre tive muita dificuldade para fila (Ana, entrevista em 21/08/2006).

Neste sentido, entendemos que os conhecimentos e os saberes utilizados pelos professores de educação 
física em suas aulas não estão relacionados exclusivamente com a sua formação acadêmica, mas também com suas vivências na escola (na qualidade de professores) e com suas experiências vividas, mesmo que anteriores ao seu ingresso na Graduação. As aulas de dança da professora Flávia, a meditação da professora Ana, as aulas de basquete do professor Carlos nos levam a pensar que suas práticas estão vinculadas a experiências anteriores.

Logo, reconhecemos a importância de considerarmos esses distintos aspectos na formação de professores de educação física e sublinhar que as experiências vividas estão presentes, também, na reflexão que realizam a partir da prática cotidiana.

Ressaltamos, inicialmente, que os conhecimentos produzidos a partir deste estudo não são passíveis de generalizaçóes. Trata-se de um estudo de caso etnográfico, situado em uma realidade específica (bairro de periferia de uma grande capital) e, finalmente, por ter sido realizado na RMEPOA, uma rede composta, em sua totalidade, por professores concursados e com formação específica para a docência.

No presente estudo compreendemos que as experiências vividas pelos professores de educação física influenciam as práticas pedagógicas na escola, seja como fonte de subsídios ou como meio de produzirem a reflexão sobre a sua prática.

Reconhecemos que, apesar de a Rede Municipal de Ensino de Porto Alegre desenvolver um amplo processo de formação permanente ${ }^{21}$, a prática pedagógica dos professores de educação física ancora-se fortemente em suas experiências, em suas diferentes dimensóes - escolarização, escolinhas esportivas, cursos que os professores realizam para subsidiar sua prática, dentre outros. Na maior parte das vezes, quando a formação inicial é citada, aparece apenas como subsídio no sentido de atividades a serem desenvolvidas com os alunos ou como algo a ser superado.

Pretendemos, com estes argumentos refletir sobre os efeitos da influência da formação inicial e permanente nas aulas desses professores e ampliar o debate sobre a relação que se estabelece entre suas experiências vividas e sua trajetória, em relação aos seus saberes e suas maneiras de organizar uma aula de educação física.
No entanto, é necessário fazer uma ressalva em relação aos professores iniciantes. Para Ana e Denis, as rotinas parecem estar se consolidando baseadas não somente em práticas que deram certo, mas nas reflexões desses professores sobre sua prática, ao buscarem conhecimentos em distintas fontes mestrado, cursos de yoga e de teatro.

Por sua vez, as rotinas desenvolvidas a partir das experiências docentes dos professores com mais tempo de docência parecem estar consolidadas, e as reflexões que desenvolvem dizem respeito a alguns aspectos específicos de sua prática, tendo, a própria prática como parâmetro. O caso da professora Glória, que havia realizado recente especialização, embora já atuasse há mais de 20 anos no magistério, parece ser exceção em relação aos seus colegas com mais tempo de docência.

A constituição da prática pedagógica dos professores de educação física pode estar relacionada aos saberes que eles produzem ao longo de seu ciclo de vida, baseados em suas experiências vividas, com ou sem uma reflexão aprofundada a partir da prática. Entendemos que os professores mobilizam um saber plural e, para TARDIF ${ }^{22}$, esta é uma das características do saber experiencial:

É um saber sincrético e plural que repousa não sobre um repertório de conhecimentos unificado e coerente, mas sobre vários conhecimentos e sobre um saber-fazer que são mobilizados e utilizados em função dos contextos variáveis e contingentes da prática profissional (p.109).

Logo, consideramos que o saber dos professores de educação física é um saber plural, que envolve aspectos relativos a distintas dimensóes. No entanto, para organizarem suas aulas estes professores não utilizam somente saberes, mas rotinas e estratégias que vão desenvolvendo ao longo de sua carreira.

A reflexão que permite a construção dos saberes, das rotinas e das estratégias parece ser de natureza e origem distintas. Pode estar baseada na própria prática, ou em conhecimentos adquiridos em distintos cursos, ou, ainda, amparada em teorias recentes, sobretudo nos casos dos professores que estavam realizando cursos de longa duração - especialização e mestrado.

Com este texto relativo à constituição das práticas pedagógicas dos professores de educação física buscase ampliar o leque de possibilidades de análise desse fenômeno extremamente complexo e multifacetado. 


\title{
Nota
}

a. O Segundo Tempo (PST) é um programa estratégico do Governo Federal, que tem por objetivo democratizar o acesso à prática e à cultura do Esporte de forma a promover o desenvolvimento integral de crianças, adolescentes e jovens, como fator de formação da cidadania e melhoria da qualidade de vida, prioritariamente em áreas de vulnerabilidade social. O PST, em sua implementação, possibilitava aos professores coordenadores a realização de um curso de especialização em Esporte Escolar, na modalidade de ensino a distância.

\begin{abstract}
Routines, strategies and knowledges of Physical Education teachers: an ethnographic case study.

In the following paper we discussed the constitution of the pedagogical practice of physical education teachers. We set out to comprehend what is the relation that is established between the life experiences of the teachers themselves and their pedagogical practice developed in a Public School in Porto Alegre. We developed an ethnographic case study, with two hundred hours of participant observation and eight interviews. The research is based on the theories of action and in the new epistemology of practice. We identified that teachers develop routines and creative strategies mainly based on their life experiences to reach their objectives in their classes and that their pedagogical practice is related to the knowledge that themselves produced during their life cycle. The study, after conclusion, was shown to the collaborators as a form to validate the research and to establish a dialogue which could provide the teachers an opportunity to reflect about their practices.
\end{abstract}

KEY WORDS: Physical education; Pedagogical practice; Life experiences; Teachers training.

\section{Referências}

1. Molina Neto V. A formação profissional em educação física e esportes. Rev Bras Cienc Esporte. 1997;19:34-41.

2. David N. A formação de professores para a educação básica: dilemas atuais para a educação física. Rev Bras Cienc Esporte. 2002;23:119-33.

3. Rezer R, organizadores. O fenômeno esportivo: ensaios críticos e reflexivos. Chapecó: Argos; 2006.

4. Oliveira C, Silva L, Molina Neto V. Arquitetura escolar e o ensino de educação física: relações (im)possíveis. Pensar Prat. 2011;14:0-0.

5. Perrenoud P. Práticas pedagógicas, profissão docente e formação: perspectivas sociológicas. Lisboa: Dom Quixote; 1993. (Temas de educação 3).

6. Perrenoud P, Paquay L, Alted M, Charlier E, organizadores. Formando professores profissionais: quais estratégias? Quais competências? 2a ed. Porto Alegre: Artmed; 2001.

7. Silva M. O habitus professoral: o objeto dos estudos sobre o ato de ensinar na sala de aula. Rev Bras Educ. 2005;29:152-63.

8. Tardif M, Gauthier C. O professor como "ator racional": que racionalidade, que saber, que julgamento? In: Perrenoud P, Paquay L, Alted M, Charlier E, organizadores. Formando professores profissionais: quais estratégias? Quais competências? 2a ed. Porto Alegre: Artmed; 2001.

9. Tardif M, Lessard C. O trabalho docente: elementos para uma teoria da docência como profissão de interações humanas. Petrópolis: Vozes; 2005.

10. Bourdieu P. Esboço de uma teoria de prática. In: Ortiz R. Pierre Bourdieu. São Paulo: Ática; 1983.

11. Lahire B. O homem plural: os determinantes da ação. Petrópolis: Vozes; 2002.

12. Gauthier C, Martineau S, Desbiens J-F, Malo A, Simard D. Por uma teoria da pedagogia: pesquisas contemporâneas sobre o saber docente. Ijuí: Unijuí; 1998.

13. Negrine A. Instrumentos de coleta de informações na pesquisa qualitativa. In: Molina Neto V, Triviños ANS, organizadores. A pesquisa qualitativa na educação física: alternativas metodológicas. Porto Alegre: Editora da Universidade; 1999. 
14. Porto Alegre (Cidade). Secretaria Municipal de Educação. Projeto Cidade Escola. [citado 2010 Jul 03]. Disponível em: http://www2.portoalegre.rs.gov.br/smed/default.php?p_secao=268.

15. García E, Cervantes C. La negociación: piedra angular de la investigación cualitativa. In: Camacho A, Fernandez-Balboa, JM, organizadores. La otra cara de la investigación: reflexiones desde la educación física. Sevilla: Wanceullen; 2004. p.109.25. 16. André MED. Etnografia da prática educativa. 2a ed. Campinas: Papirus; 1998.

17. Hargreaves A. Profesorado, cultura y postmodernidad: cambian los tempos, cambia el profesorado. Madrid: Morata; 1996. 18. Wittizorecki ES, Molina Neto V. O trabalho docente dos professores de educação física na rede municipal de ensino de Porto Alegre. Rev Mov. 2005;11:47-70.

19. Woods P. La escuela por dentro: la etnografía en la investigación educativa. Paidós, MEC; 1995. (Temas de Educacion). 20. Pérez Gómez A. O pensamento prático do professor: a formação do professor como profissional reflexivo. In: Nóvoa A. Os professores e a sua formação. 2a ed. Lisboa: Dom Quixote; 1995.

21. Günther MCC, Molina Neto V. Formação permanente de professores de educação física na rede municipal de ensino de Porto Alegre: uma abordagem etnográfica. Rev Paul Educ Fís. 2000;14:72-84.

22. Tardif M. Saberes docentes e formação profissional. Petrópolis: Vozes; 2002

ANEXO 1 - Caracterização dos professores participantes da pesquisa.

\begin{tabular}{|c|c|c|c|c|c|}
\hline Nome & $\begin{array}{c}\text { Horas de trabalho } \\
\text { semanais na escola/ } \\
\text { ciclo }\end{array}$ & $\begin{array}{c}\text { Horas de trabalho } \\
\text { semanais fora } \\
\text { da escola }\end{array}$ & $\begin{array}{l}\text { Outros envolvimentos } \\
\text { profissionais }\end{array}$ & $\begin{array}{c}\text { Tempo de serviço } \\
\text { na RME/POA }\end{array}$ & $\begin{array}{c}\text { Tempo de serviço } \\
\text { no magistério }\end{array}$ \\
\hline Ana & 20 horas $/ 1^{\circ}$ ciclo & Não informado & $\begin{array}{l}\text { Yoga e personal } \\
\text { training }\end{array}$ & 2,5 anos & 2,5 anos \\
\hline Beto & 30 horas $/ 3^{\circ}$ ciclo & 20 horas & Escola Pública Estadual & 3 anos & 20 anos \\
\hline Carlos & 20 horas $/ 3^{\circ}$ ciclo & 40 horas & $\begin{array}{c}\text { Secretaria Municipal } \\
\text { de Esportes }\end{array}$ & 30 anos & 30 anos \\
\hline Denis & 40 horas $/ 3^{\circ}$ ciclo & Não tem & $\begin{array}{c}\text { Mestrando da } \\
\text { Universidade Federal } \\
\text { do Rio Grande do Sul - } \\
\text { Faculdade de Educação }\end{array}$ & 2,5 anos & 3 anos \\
\hline Eliane & 30 horas $/ 1^{\circ}$ ciclo & Não tem & Não tem & 19 anos & 21 anos \\
\hline Flávia & 10 horas $/ 2^{\circ}$ ciclo & 30 horas & RMEPOA & 19 anos & 19 anos \\
\hline Glória & 10 horas $/ 2^{\circ}$ ciclo & 20 horas & RMEPOA & 15 anos & 25 anos \\
\hline Gabriela & $\begin{array}{l}40 \text { horas/Na Escola: } \\
\text { escolinha de voleibol e } \\
\text { coordenadora de turno }\end{array}$ & Não tem & Náo tem & Não informado & Não informado \\
\hline
\end{tabular}

\section{Agradecimentos}

Apoio financeiro do CNPq.

\begin{tabular}{r|l} 
ENDEREÇo & \\
Mônica Urroz Sanchotene & Recebido para publicação: 15/03/2012 \\
R. Livramento, 409 & 1a. Revisão: 22/10/2012 \\
90640-130 - Porto Alegre - RS - BRASIL & 2a. Revisão: 08/02/2013 \\
e-mail: msanchotene@yahoo.com.br & Aceito: 25/03/2013 \\
&
\end{tabular}

